\title{
Knowledge, Attitude and Practice on CPR Among Dental Students
}

\author{
Harita Ravikumar' ${ }^{1}$ R. Gayatri Devi ${ }^{2}$ and A. Jothi Priya ${ }^{3}$ \\ ${ }^{1}$ Department of physiology Saveetha Dental College, Saveetha Institute of Medical \\ and Technical Sciences (SIMATS) Saveetha University, Chennai, India \\ ${ }^{2}$ Department of physiology Saveetha dental college, Saveetha Institute of Medical \\ and Technical Sciences (SIMATS) Saveetha University, Chennai, India \\ ${ }^{3}$ Department of physiology Saveetha dental college, Saveetha Institute of Medical \\ and Technical Sciences (SIMATS) Saveetha University, Chennai, India
}

\section{ABSTRACT}

Cardio Pulmonary Resuscitation (CPR) is one of the most important methods to save a person's life when they have undergone cardiac arrest. This is an emergency procedure that combines chest compression often with artificial ventilation which is used to supply continuous blood circulation to the brain and helps in breathing. CPR is majorly done due to medical emergencies but sometimes it was done due to dental emergencies too. There are possibilities where patients can undergo cardiac arrest in the dental chair and CPR could be a life saver. This study aims to assess the knowledge, attitude and practice on Cardiopulmonary Resuscitation among the dental students. This survey included 100 participants through survey monkey- an online survey. The participants' knowledge was analyzed by their responses to 10 questions which was selected pertaining to the topic, Cardiopulmonary Resuscitation. The result showed that even though most of them had good knowledge, it can be seen that they weren't confident enough to serve. Since most dental students lack practice and knowledge on CPR, there is a need for practise of CPR to the undergraduate students which helps them to gain more knowledge and improve in their career.

\section{KEY WORDS: CPR, DENTAL STUDENTS, PRACTICE, BASIC LIFE SUPPORT, DENTAL EMERGENCIES.}

\section{INTRODUCTION}

Basic life support (BLS) is a simple life saving method after a cardiac arrest. It is a very integrated method which involves ventilation and circulation until the cause is found and stopped (Alotaibi et al., 2016). Cardiac and respiratory arrest are the most common emergencies

\section{ARTICLE INFORMATION}

*Corresponding Author: gayatri.physio88@gmail.com Received 29th July 2020 Accepted after revision 28th Sep 2020 Print ISSN: 0974-6455 Online ISSN: 2321-4007 CODEN: BBRCBA

Thomson Reuters ISI Web of Science Clarivate Analytics USA and Crossref Indexed Journal

\section{Clarivate
Analytics}

NAAS Journal Score 2020 (4.31) SJIF: 2020 (7.728)

A Society of Science and Nature Publication,

Bhopal India 2020. All rights reserved.

Online Contents Available at: http//www.bbrc.in/

Doi: http://dx.doi.org/10.21786/bbrc/13.8/182 that doctors face in the hospitals in which complications and high death rate can be prevented by simple and clever technique (Devishree, Mahesh and Jain, 2018). The most common emergencies on dental chairs are syncope, postural hypotension, swallowed foreign bodies, anaphylaxis, cardiac arrest, bronchospasm, hypoglycemia and seizures (Ahamed and Kumar, 2016). Hence the dental practitioner should be a good communicator and be able to recognize the problems and also have an adequate knowledge of the medical emergencies and how to cope up with it (Haas, 2006). BLS consist of the following steps: initial assessment, airway maintenance, expired air ventilation (i.e.: rescue breathing; mouth-to -mouth ventilation) and at last chest compression (Somaraj et al., 2017).

Previous Studies on Basic Life Support were conducted on clinical students, dental interns, post graduate students

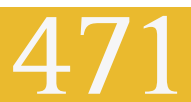


and faculty which resulted that post graduate students and faculties having poor knowledge when compared to undergraduate students and dental interns. Lack of practice and knowledge on CPR can be the reason for dental faculties and postgraduate students (Gonzaga et al., 2003). Studies conducted on 6th year japan students resulted in 84\% students not performing standard CPR. In Pakistan the students showed that significantly less students had skills on CPR. Study conducted on medical students showed that their knowledge on BLS was much shorter (Okonta and Okoh, 2015). In Saudi the female health college students were under presented and also they lack BLS knowledge and practice (Al-Mohaissen, 2017). It has also seen that more than half of the dental students were not able to perform cardiopulmonary resuscitation properly (Sharma et al., 2019).

Studies conducted for 126 dental interns and practitioners resulted in none having complete knowledge of BLS (Mohan et al., 2015). Previously our department has published extensive research on various aspects of physiological aspects (Harsha et al., 2015; Renuka and Sethu, 2015; Samuel and Devi, 2015; Swathy and Sethu, 2015; Choudhari and Jothipriya, 2016; Dave and Others, 2016; Fathima, 2016; Ilankizhai and Devi, 2016; Baheerati and R, 2018; R and Sethu, 2018; Shruthi and Preetha, 2018; A. J. Priya, Devi and Others, 2019; Iyer, Devi and Priya, 2019; J. Priya, Devi and Others, 2019; Timothy, Devi and Priya, 2019) this vast research experience has inspired us to research CPR. As the number of deaths increased due to lack of awareness about CPR, this study was aimed to assess the knowledge, attitude and practice of CPR among dental students and prevent such disasters from occurring.

\section{MATERIAL AND METHODS}

This cross-sectional study was conducted in Saveetha Dental College and Hospitals which was conducted by assessing responses to the 10 selected questions which was created pertaining to Cardiopulmonary Resuscitation. The survey was carried out among 100 dental college students. The aim of this study was explained in detail to the participants and a questionnaire was circulated through an online survey link where they had to submit their responses. Data was collected and analyzed in statistics.

\section{RESULTS AND DISCUSSION}

In the present study, 74\% of the dental college students responded that they were aware of CPR and 26\% were not aware (Figure 1). Figure 2 asks the students whether they had undergone CPR training where 55\% had gone for the training and 45\% didn't. Figure 3 showed that whether the students had given CPR to a patient before, only $12 \%$ of them had given and $88 \%$ hadn't. Figure 4 is the types of CPR and 50\% of the students had chosen 3 types and 50\% had chosen 2 types. In figure 5 shows who should lead the procedure, 54\% chose anyone who has knowledge of CPR and 46\% chose only a dentist. Figure 6 shows the posture of the patient to whom CPR to be given and students of $64 \%$ had chosen that placing a stool underneath, placing a cardiac board and 36\% students chose there's no particular posture. Figure 7 showed the rate of CPR to be given, $46 \%$ students chose 60-70 per minute and 54\% students chose $100-120$ per minute. Figure 8 showed the ratio of chest compression famed ventilation where $39 \%$ of students chose options containing 10:20 and 61\% of people chose 30:2. Figure 9 showing the percentage of CPR as medical emergencies in dental practice and 32\% chose its 0.3\% whereas 68\% chose its 50\%. 77\% of students said that this survey was very helpful and 23\% of people didn't benefit, shows in figure 10. There was an association between gender and posture of CPR to be followed in the dental chair, the percentage of CPR as a dental emergency (Figure 11, Figure 12).

Figure 1: Pie chart showing the percentage distribution of the student's awareness on CPR. Majority of the participants 74\% have answered yes (red), 26\% have answered no (blue).

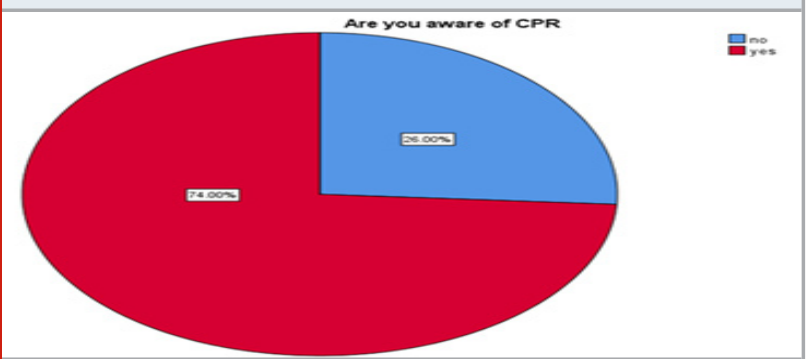

Figure 2: Pie chart showing the percentage distribution of students who have undergone CPR training. Majority of the participants 55\% responded yes (red), 45\% responded no (blue).

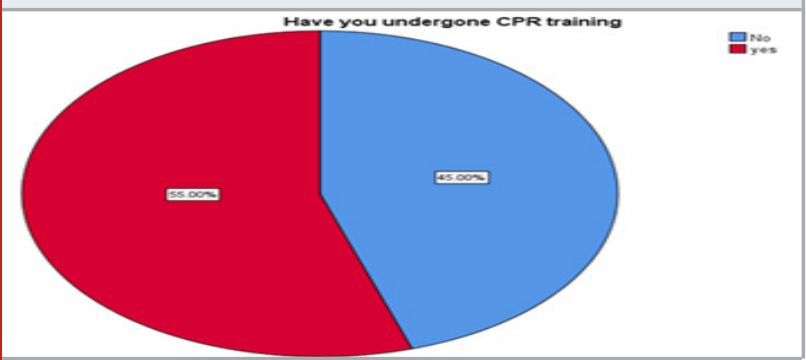

Figure 3: Pie chart showing the percentage distribution of student's experience on giving CPR. Majority of the participants $88 \%$ responded no (blue), 12\% responded yes (red).

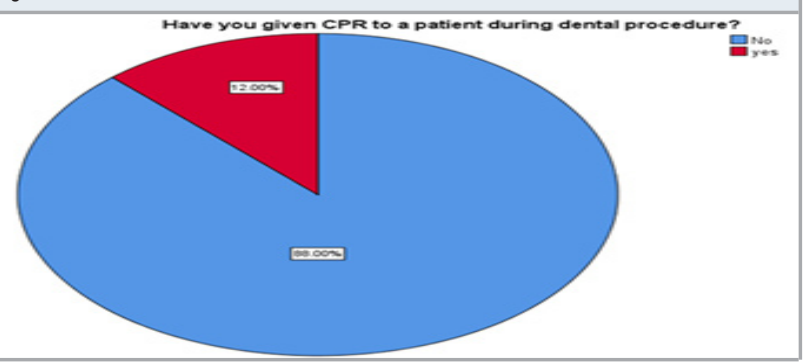


Figure 4: Pie chart showing the percentage representation of the participant's knowledge on types of CPR. Majority of participants 50\% have answered 3 (red) and 50\% have answered 2 (blue).

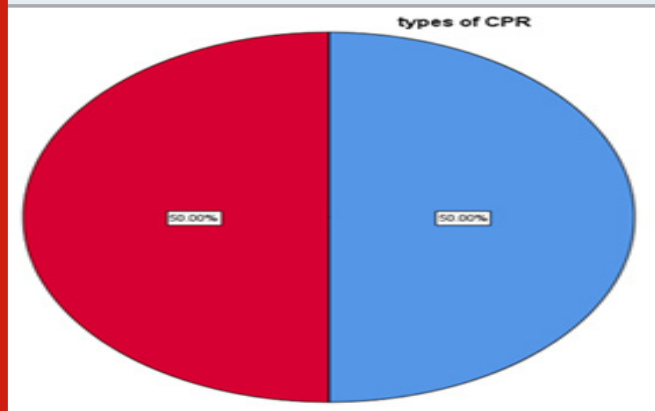

블

Figure 5: Pie chart showing the percentage distribution of the participants' knowledge on whom should lead the procedure. Majority 54\% responded that anyone who has the knowledge (blue), 46\% responded that only a dentist should lead (red).

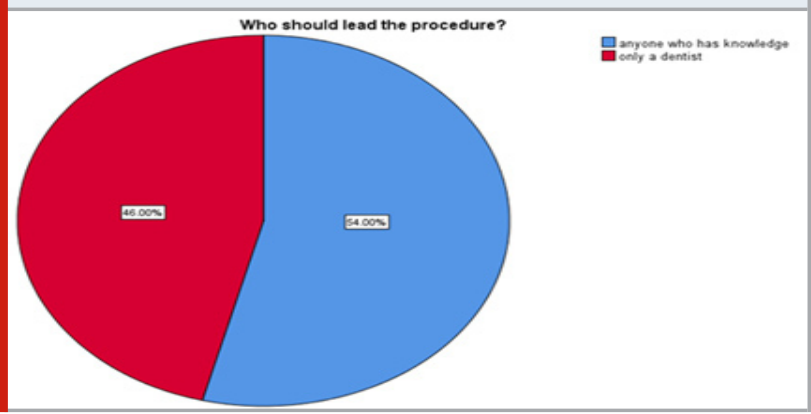

Figure 6: Pie chart showing the percentage distribution of student's knowledge on the posture of CPR on dental chair. Majority of the participants 64\% responded that placing a stool underneath and using a cardiac board (blue), 36\% responded to proceed as such (red).

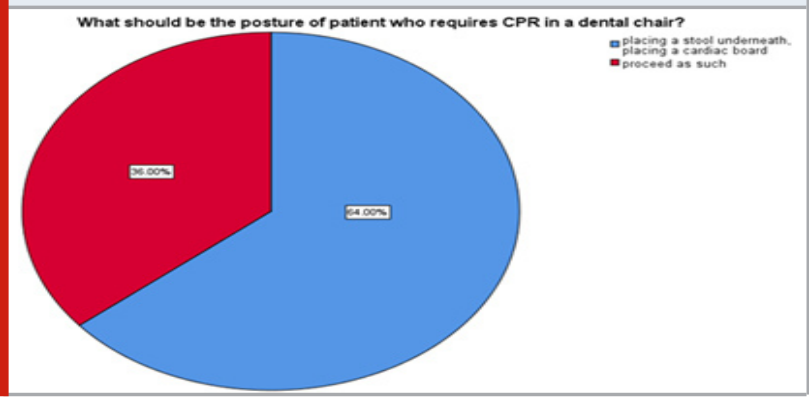

Regina M. Carvalho et al stated the purpose of the spiral curriculum for revising the subject and also the assumption of confidence in students when they are more trained on basic life support. Undergraduate students visiting hospitals and giving Basic Life Support has helped them in improving the medical emergencies (Carvalho, Costa and Marcelo, 2008). The research resulted in there is lack of knowledge and practice which was also mentioned in AM Owojuyigbe et al where he stated the requirement of training in BLS (Owojuyigbe et al., 2015). Also in
Mittal R Savaliya et al mentioned the need for training in management of medical emergencies (Savaliya, Vora and Gorynwala, 2016). Sangamesh et al stated that most of them were aware of BLS and had a positive attitude towards it (Sangamesh et al., 2017). Elanchelian et al also stated that there is a need for medical emergency training (Elanchezhiyan et al., 2013).

Figure 7: Pie chart showing the percentage distribution of student's knowledge on rate of CPR given. Majority of the participants 54\% responded 100-120 per minute (blue), 46\% responded 100-120 per minute (red).

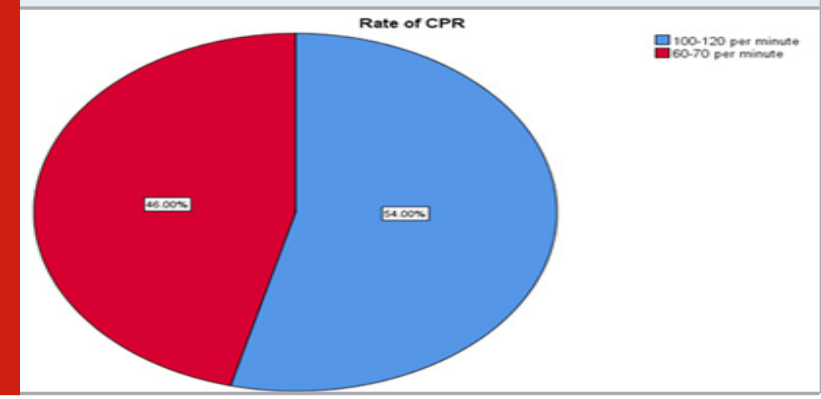

Figure 8: Pie chart showing the percentage distribution of student's knowledge on ratio of chest compression and ventilation. Majority of the participants 61\% responded 30:2 (red), 39\% responded 10:20 (blue).

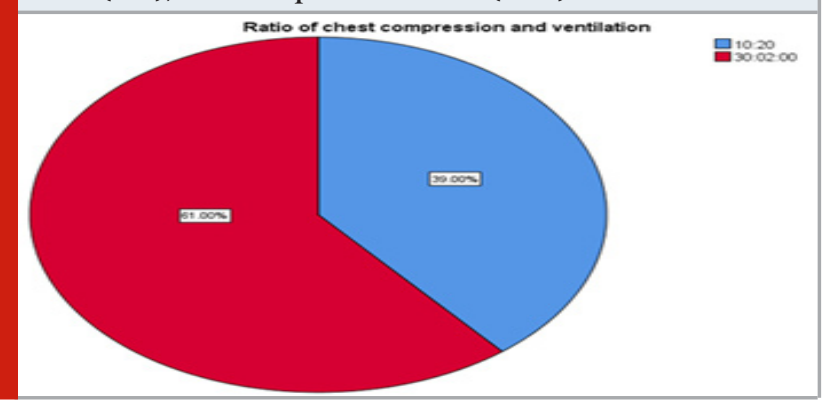

Figure 9: Pie chart showing the percentage distribution of student's awareness on percentage of CPR in dental practice. Majority of the participants $68 \%$ responded 50\% (red), 32\% responded 0.3\% (blue).

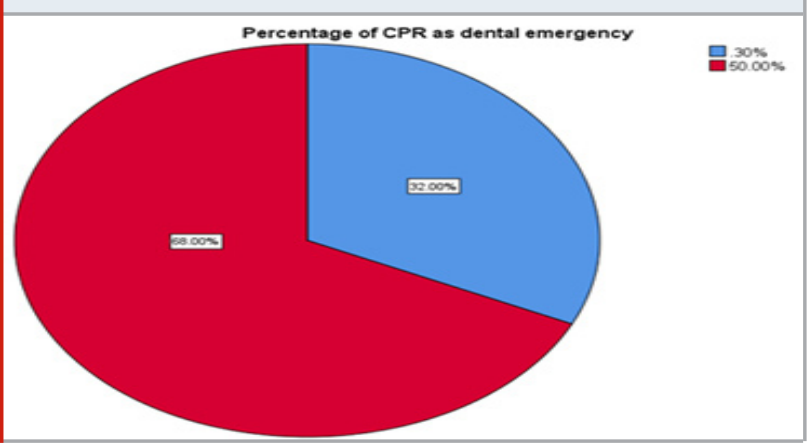

Comparing with the result that Sudeep et al had obtained, more than $60 \%$ of the responders have scored below $50 \%$ (Sudeep et al., 2013). Dhage Pundalika et al mentioned that 57.9\% had positive attitudes, 19\% had good knowledge and 62.7\% had average knowledge (Narayan 
et al., 2015). Chew et al had stated that $29 \%$ mentioned to perform CPR under any circumstances of cardiac arrest, 69\% said that they would call an ambulance and 16\% of school teachers told that they would perform CPR (Chew et al., 2009). Ragava Sharma et al stated that all of the responders were aware of BLS and its usefulness, $44 \%$ of the medical interns scored less than 50\% and 88\% dental interns had poor knowledge (Sharma and Attar, 2012). Neha Baduni et al mentioned 25\% were faculties, $14.42 \%$ were resident doctors and 30.77\% were dental students. Among them none had good knowledge 26.96\% has correct sequence neonates (Baduni et al., 2014). These previous studies and surveys had helped in understanding the lacunae and when compared to the survey done, it can be observed that similar results were obtained. This shows a lack of knowledge and practice of CPR and the need to increase the awareness among dental students.

Figure 10: Pie chart showing the percentage of student's thoughts on this survey whether it was helpful. Majority of the participants $77 \%$ responded yes (red), 23\% responded no (blue).

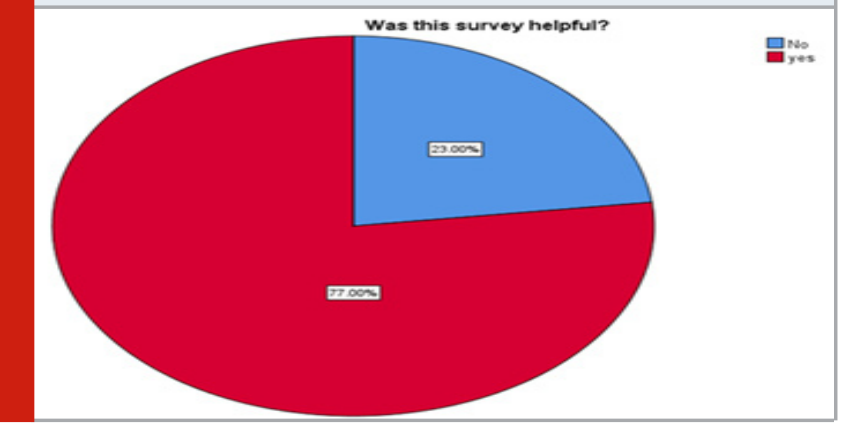

Figure 11: The bar showing the association between gender and the posture of CPR to be followed in the dental chair. $\mathrm{X}$-axis represents the gender and $\mathrm{Y}$-axis represents the number of respondes. Majority of the female participants have mentioned placing a stool and cardiac board underneath. p-value: 0.652 (>0.05) indicating statistically not significant.

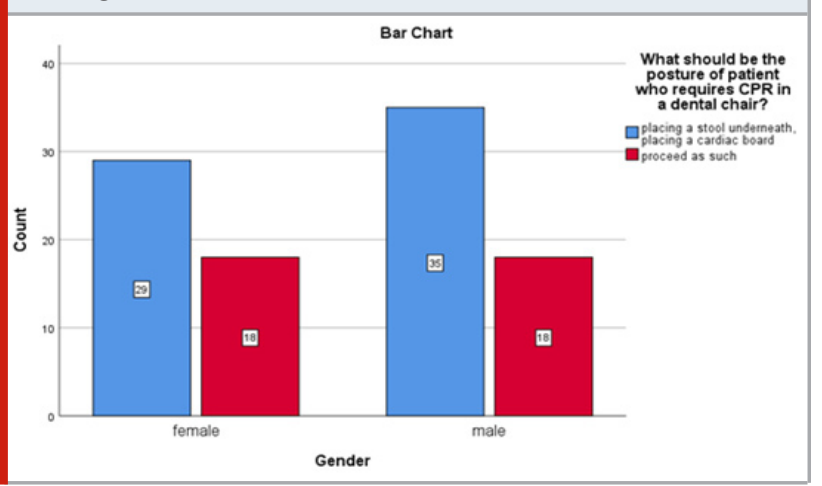

\section{CONCLUSION}

From this survey, it is evident that the majority of them are aware about it but lack in practice. There is a need to increase the awareness among dental students thereby it
Figure 12: The bar showing the association between gender and the percentage of CPR as a dental emergency. $\mathrm{X}$-axis represents the gender and $\mathrm{Y}$-axis represents the number of respondes. Majority of the male participants have responded 50\% than female. p-value: 0.680 (>0.05) indicating statistically not significant.

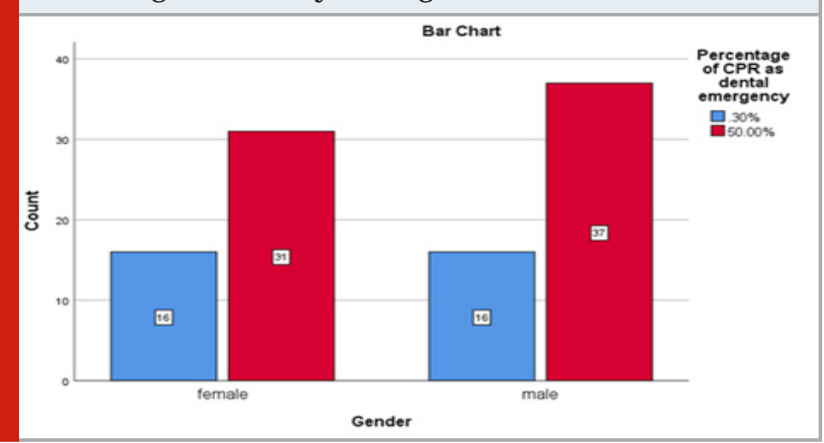

can change their attitude where they become much more confident and increase their efficiency in practice.

\section{ACKNOWLEDGEMENTS}

The authors would like to acknowledge the help and support rendered by the study participants for the accomplishment of the study.

Conflict of Interest: None declared.

\section{REFERENCES}

Ahamed, A. and Kumar, M. P. S. (2016) 'Knowledge, attitude and perceived confidence in handling medical emergencies among dental students', Research journal of pharmaceutical, biological and chemical sciences. Journal of Pharmaceutical Sciences and Research, 8(7), p. 645.

Al-Mohaissen, M. A. (2017) 'Knowledge and Attitudes Towards Basic Life Support Among Health Students at a Saudi Women's University', Sultan Qaboos University medical journal. ncbi.nlm.nih.gov, 17(1), pp. e59-e65. Alotaibi, 0. et al. (2016) 'Basic life support: Knowledge and attitude among dental students and Staff in the College of Dentistry, King Saud University', The Saudi Journal for Dental Research. Elsevier, 7(1), pp. 51-56. Baduni, N. et al. (2014) 'Awareness of basic life support among dental practitioners', National journal of maxillofacial surgery. ncbi.nlm.nih.gov, 5(1), pp. 19-22.

Baheerati, M. M. and R, G. D. (2018) 'Obesity in relation to Infertility', Research Journal of Pharmacy and Technology. Journal of Ravishankar University (Part-B), 11(7), pp. 3183-3185.

Carvalho, R. M., Costa, L. R. and Marcelo, V. C. (2008) 'Brazilian dental students' perceptions about medical emergencies: a qualitative exploratory study', Journal of dental education. Wiley Online Library, 72(11), pp. 
1343-1349.

Chew, K. S. et al. (2009) 'Translating knowledge to attitude: a survey on the perception of bystander cardiopulmonary resuscitation among dental students in Universiti Sains Malaysia and school teachers in Kota Bharu, Kelantan', The Medical journal of Malaysia. europepmc.org, 64(3), pp. 205-209.

Choudhari, S. and Jothipriya, M. A. (2016) 'Nonalcoholic fatty liver disease', Research Journal of Pharmacy and Technology. unknown, 9(10), p. 1782.

Dave, P. H. and Others (2016) 'Pathogenesis and Novel Drug for Treatment of Asthma-A Review', Research Journal of Pharmacy and Technology. A \& V Publications, 9(9), pp. 1519-1523.

Devishree, R. A., Mahesh, R. and Jain, A. R. (2018) 'Knowledge about Basic Life Support (BLS) in Pediatric Patient among Dental Students', Research journal of pharmaceutical, biological and chemical sciences. Journal of Pharmaceutical Sciences and Research, 10(2), pp. 278-281.

Elanchezhiyan, S. et al. (2013) 'Awareness of dental office medical emergencies among dental interns in southern India: an analytical study', Journal of dental education. Wiley Online Library, 77(3), pp. 364-369. Fathima, F. (2016) 'Preetha. Evaluation of Thyroid Function Test in Obese Patients', Asian J Pharm Clin Res, 9(3), pp. 353-355.

Gonzaga, H. F. de S. et al. (2003) 'Evaluation of knowledge and experience of dentists of São Paulo State, Brazil about cardiopulmonary resuscitation', Brazilian dental journal. SciELO Brasil, 14(3), pp. 220-222.

Haas, D. A. (2006) 'Management of Medical Emergencies in the Dental Office: Conditions in Each Country, the Extent of Treatment by the Dentist', Anesthesia progress. Allen Press, 53(1), pp. 20-24.

Harsha, L. et al. (2015) 'Systemic approach to management of neonatal jaundice and prevention of kernicterus', Research Journal of Pharmacy and Technology. A \& V Publications, 8(8), pp. 1087-1092. Ilankizhai, R. J. and Devi, G. (2016) 'Role of environmental factors on sleep patterns of different age groups: A survey-based study', Asian J Pharm Clin Res, 9, pp. 124-126.

Iyer, P. K., Devi, R. G. and Priya, A. J. (2019) 'A Survey Study on Causes, Treatment and Prevention of Onychocryptosis', Indian Journal of Public Health Research \& Development. Prof.(Dr) RK Sharma, 10(8), pp. 807-811.

Mohan, M. et al. (2015) 'Awareness of basic life support (BLS) among Dental interns and Dental practitioners', Journal of Health and Allied Sciences NU. Thieme Medical and Scientific Publishers Private Ltd., 5(03), pp. 014-018.

Narayan, D. P. R. et al. (2015) 'Assessment of knowledge and attitude about basic life support among dental interns and postgraduate students in Bangalore city, India', World journal of emergency medicine. ncbi.nlm. nih.gov, 6(2), pp. 118-122.

Okonta, K. E. and Okoh, B. A. N. (2015) 'Theoretical knowledge of cardiopulmonary resuscitation among clinical medical students in the University of Port Harcourt, Nigeria', African Journal of Medical and Health Sciences. Medknow Publications and Media Pvt. Ltd., 14(1), p. 42.

Owojuyigbe, A. M. et al. (2015) 'Impact of basic life support training on the knowledge of basic life support in a group of Nigerian Dental Students', The Nigerian postgraduate medical journal. npmj.org, 22(3), pp. 164-168.

Priya, A. J., Devi, G. and Others (2019) 'Physical Fitness among the Dental Physician, Dental Undergraduates and Postgraduates Students', Indian Journal of Public Health Research \& Development. Prof.(Dr) RK Sharma, 10(10), pp. 223-226.

Priya, J., Devi, G. and Others (2019) 'Evaluation of Muscular Endurance among Dentists', Indian Journal of Public Health Research \& Development. search. ebscohost.com, 10(10). Available at: http://search. ebscohost.com/login.aspx? direct=truectprofile=ehostct scope $=$ site\&tauthtype $=$ crawler\&tjrnl $=09760245 \& A N=1$ 40756206cth=G4SC\%2FJ8z\%2BUHFuuTbV4UFDCYnk 6MKUTskQkH7kGxLd3EgnLZ4lb\%2FVDEMrZPtKML9 s6AouBNijcz\%2BNcfv3UaNBkw\%3D\%3DEtcrl=c.

Renuka, S. and Sethu, G. (2015) 'Regeneration after Myocardial Infarction', Research Journal of Pharmacy and Technology. A \& V Publications, 8(6), pp. 738741.

R, G. D. and Sethu, G. (2018) 'EVALUATION OF ADENOIDS BY ORONASAL AND NASAL SPIROMETRY', Asian Journal of Pharmaceutical and Clinical Research, pp. 272-274.

Samuel, A. R. and Devi, M. G. (2015) 'Geographical distribution and occurrence of Endemic Goitre', Research Journal of Pharmacy and Technology. A \& V Publications, 8(8), pp. 973-978.

Sangamesh, N. C. et al. (2017) 'Awareness, Attitude, and Knowledge of Basic Life Support among Medical, Dental, and Nursing Faculties and Students in the University Hospital', Journal of International Society of Preventive \&t Community Dentistry. ncbi.nlm.nih. gov, 7(4), pp. 161-167.

Savaliya, M. R., Vora, M. B. and Gorynwala, S. N. (2016) 'An evaluation of knowledge and practices toward the basic life support/cardiopulmonary resuscitation among undergraduate dental students', International Journal of 
Students' Research. Medknow Publications and Media Pvt. Ltd., 6(2), p. 12.

Sharma, P. et al. (2019) 'Knowledge, attitude, and practices of dental students regarding medical emergency preparedness in Paonta Sahib, Himachal Pradesh', International Journal of Community Dentistry. Medknow Publications and Media Pvt. Ltd., 7(1), p. 11.

Sharma, R. and Attar, N. R. (2012) 'Adult basic life support (BLS) awareness and knowledge among medical and dental interns completing internship from deemed university', Journal of Health and Allied Sciences NU. Thieme Medical and Scientific Publishers Private Ltd., 2(03), pp. 06-13.

Shruthi, M. and Preetha, S. (2018) 'Effect of Simple Tongue Exercises in Habitual Snorers', Research Journal of Pharmacy and Technology. A \& V Publications, 11(8), pp. 3614-3616.
Somaraj, V. et al. (2017) 'Knowledge, attitude and anxiety pertaining to basic life support and medical emergencies among dental interns in Mangalore City, India', World journal of emergency medicine. ncbi.nlm. nih.gov, 8(2), pp. 131-135.

Sudeep, C. et al. (2013) 'Awareness of basic life support among students and teaching faculty in a dental college in Coorg, Karnataka', International Dental Journal of Students Research. International Dental Journal of Students Research, 2, pp. 04-21.

Swathy, S. and Sethu, V. G. (2015) 'Acupuncture and lower back pain', Research Journal of Pharmacy and Technology. A \&t V Publications, 8(8), pp. 991-993.

Timothy, C. N., Devi, R. G. and Priya, A. J. (2019) 'Evaluation of Peak Expiratory Flow Rate (PEFR) in Pet Owners', Indian Journal of Public Health Research At Development. Prof.(Dr) RK Sharma, 10(8), pp. 803806. 